\title{
Mixing Worlds
}

\section{Current Trends in Integrating the Past and Present through Augmented and Mixed Reality}

\author{
Jiafang Liang $\odot$
}

\section{OVERVIEW}

Spatial and shape data represented by 3D digital models have become a central component of our archaeological datasets. Immersive visual and audio interaction with these models offers an intuitive way to use these data. The mixing of the virtual with the real world suits archaeological work particularly well, and the technologies of augmented reality (AR) and mixed reality (MR) enable this type of interaction. Much past work on these technologies has involved public engagement, but they also hold the potential for valuable deployment directly in archaeological practice and research, especially the seamless integration offered by MR. This review examines the range of experiments archaeologists are currently undertaking with $A R$ and $M R$, and it looks to the future applications of these technologies.

Among all the types of digital data regularly collected by archaeologists, the largest and most complex type-group usually consists of three-dimensional (3D) models. A typical photogrammetric capture of a trench or site can easily contain tens of millions of points that connect to form a triangle mesh wrapped in a photorealistic texture. Models of spaces and objects captured by photogrammetry, lidar, or structured light are also detailed and highly precise. This raises the question, What do we do with all these 3D models containing such abundant data? Spatial and morphometric analyses are naturally central to archaeological research, but software for undertaking this type of work in 3D remains challenging to use. For humans, moving from the interface of a $2 D$ screen to a more realistic 3D environment could support more intuitive interaction with the data (Figure 1). Although the closed environment of virtual reality (VR) has its purposes, given that archaeology inherently deals with the real world and objects that exist around us in the present, the ability to mix the virtual and the real may hold more potential for future applications-including in the classroom, during field excavation training, and for heritage or data interpretation (Figure 2). Here, we review these types of mixed worlds, enabled by augmented reality (AR) and mixed reality (MR) technologies. Although we may be years or even over a decade away from hardware that allows truly seamless integration of the real and virtual, we should now consider where we are and where we are headed.

\section{DEFINITIONS AND HARDWARE}

Over the last decade, many people have had an opportunity to try the new generation of virtual reality devices. VR completely closes off a view of the real world from the user, allowing for full immersion in the virtual environment through sight and sound (Burdea and Coiffet 2003). One can imagine several useful implementations of VR in archaeology, such as for public education (Ellenberger 2017). Given that archaeologists build interpretations from real objects and spaces, however, technologies that enable the mixing of real evidence with interpretation may better fit our research. Augmented reality (AR) and mixed reality (MR) allow for the visual placement of virtual computer graphics within the real world, with which the user can interact in real time (Azuma 1997). The relative weight of reality and virtuality in the scene depends on the program design (Speicher et al. 2019). There remains some ambiguity about the specific differences between $A R$ and $M R$, as well as their relative placement on an extended reality (XR) spectrum (Milgram et al. 1995). For our purposes, we define $A R$ as the simpler implementations that add information or graphics to an environment, whereas MR allows for more sophisticated, spatially aware, and immersive interactions between the virtual and the real.

The difference between AR and MR may be more meaningfully reflected in the various hardware implementations. Many of the latest smartphones and tablets, for example, enable basic AR through software that can place virtual objects into a live view from the camera (Figures 3 and 4). This functionality can also be used to place information virtually into an environment-including text and video "pop-up" introductions to objects and spaces at an archaeological site. Given that most people carry a smartphone with satellite positioning capabilities, AR offers a low barrier to entry for deployment at any site (Jayawardena and Perera 2016). Because of its greater accessibility, AR has also seen much more research focus from archaeologists than MR. MR, on the other hand, works with

Advances in Archaeological Practice 9(3), 2021, pp. 250-256

Copyright (C) The Author(s), 2021. Published by Cambridge University Press on behalf of Society for American Archaeology DOI:10.1017/aap.2021.16 


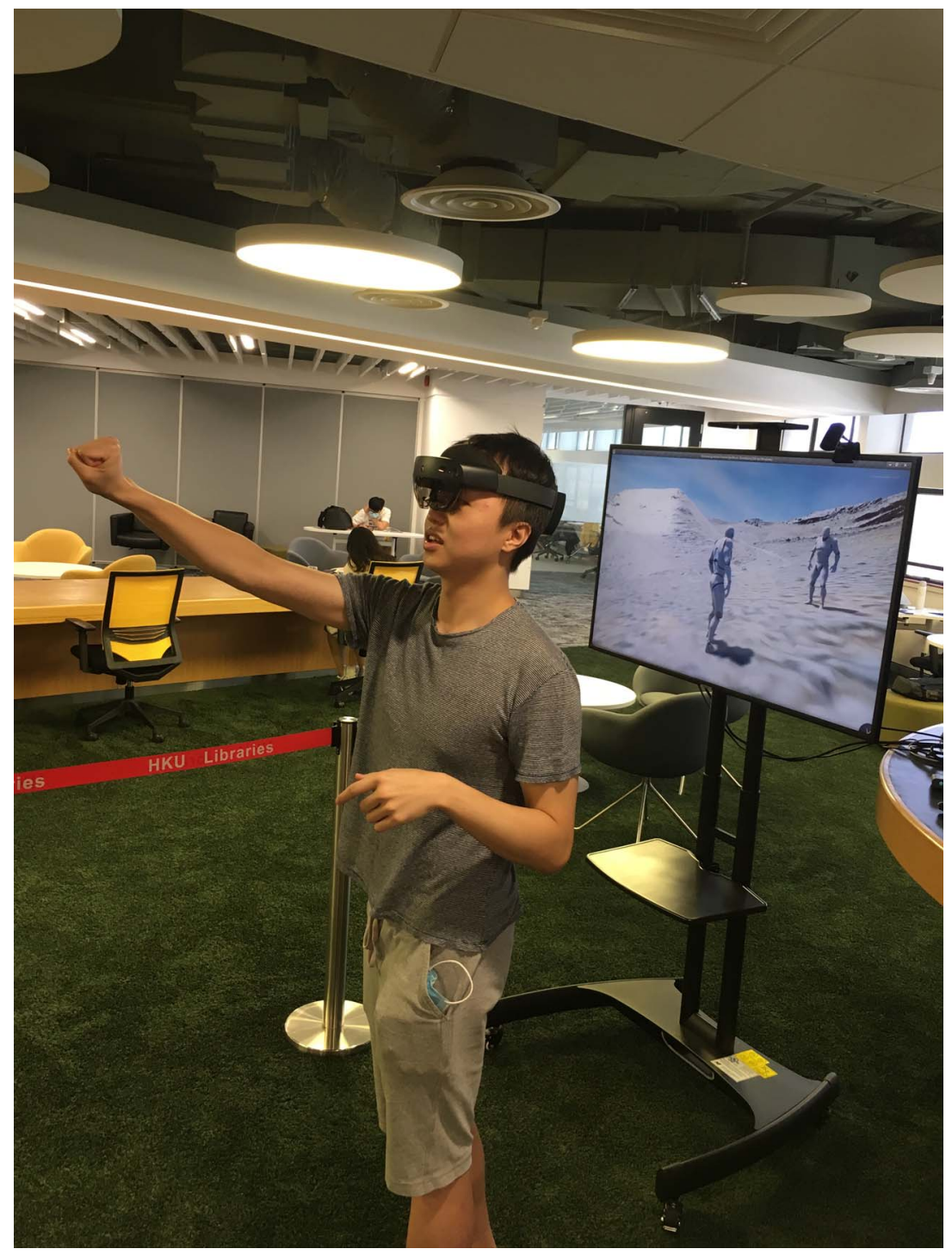

FIGURE 1. University of Hong Kong undergraduate student Ryushi Kiyama (城山龍志) is using the Microsoft HoloLens 2 to interact with an archaeological site (photo by Fong Tsz Ching Phoebe).

hardware that places transparent digital screens directly in the view of both eyes by using a head-mounted device (HMD), thereby enabling a stereoscopic 3D view of the virtual world superimposed on the real world (Figure 5). Together with directional audio, this enables a multisensory and fully immersive MR environment, where virtual objects are placed seamlessly into the real world from the perspective of the user. MR HMDs have only come to market in the last few years, and they still face several limitations—such as a small field of view-given the enormous processing power required to both create real-time virtual objects and map the spatial layout of the local environment. The Microsoft HoloLens 2 (Figure 1) is currently the most widely available device, but various other vendors have developed this technology or are planning to enter the market in the next few years (Aniwaa Pte. Ltd 2021; Fathi 2021). These types of HMD should be distinguished from less sophisticated smartglasses that place a small phone-like screen in the peripheral view to convey information.

\section{THE RANGE OF APPLICATIONS FOR AR AND MR IN ARCHAEOLOGY}

Over the last decade, interest has been building in the deployment of $A R$ and MR for studying the past. For example, Bekele and colleagues (2018) surveyed applications in the broader cultural heritage field and found that AR was most often used to enhance public exhibits, but it was also used for the reconstruction of everything from paintings to statues. Within archaeology, research has progressed in a variety of directions regarding the application of AR to our field. In a prior review, Ellenberger (2017) highlighted how AR can be deployed in public engagement and education. Keil and colleagues (2013) experimented with AR in the Athens Acropolis Museum, which included recoloring the actual ancient objects, and Amakawa and Westin (2018) emphasized that the virtual can help compensate for telling the past of people who 


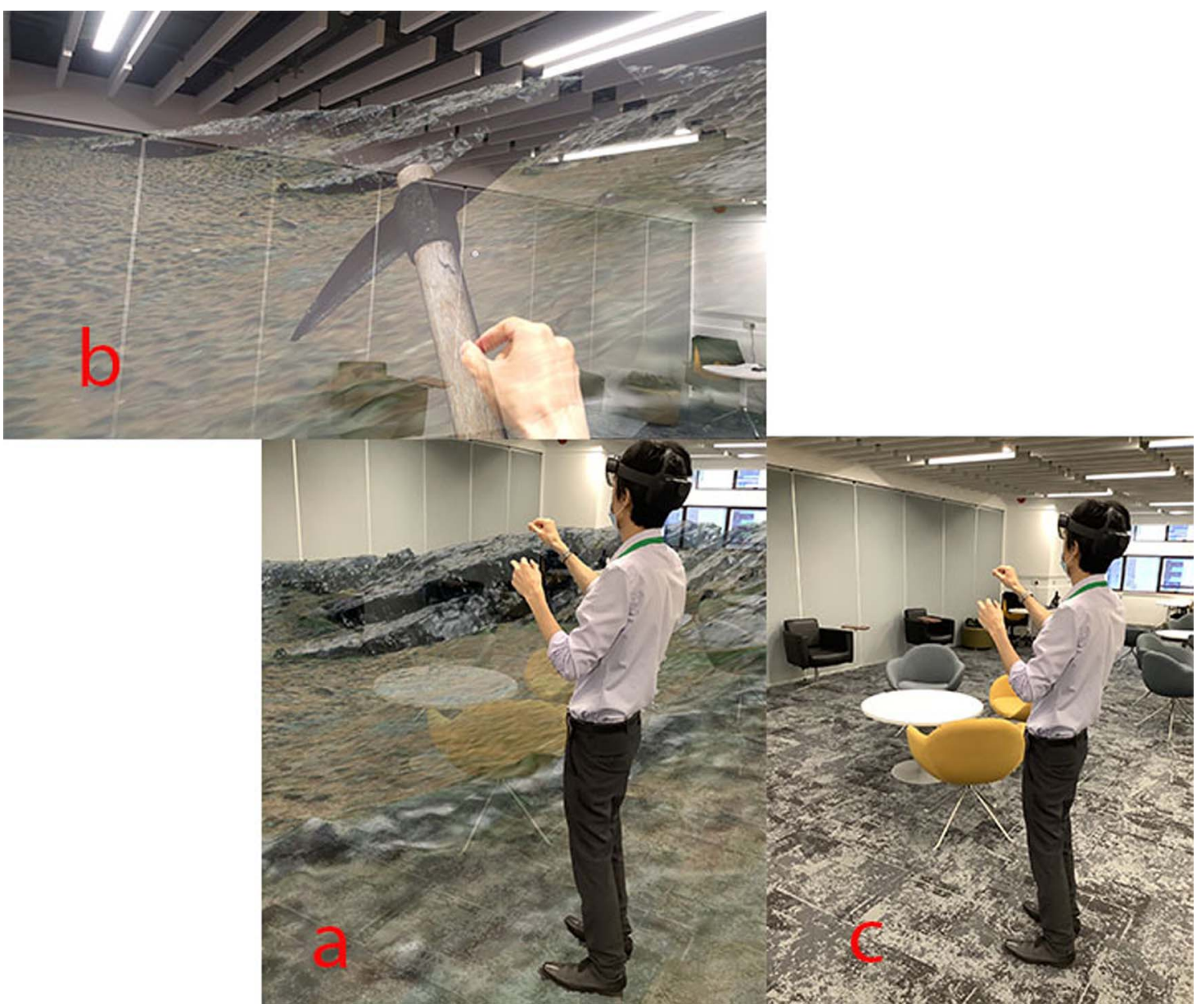

FIGURE 2. These images demonstrate different views displayed while Wong Chi-him Leo takes an AR tour of an archaeological site with the HoloLens 2. (a) Site superimposed in a real indoor environment by the HoloLens 2; (b) view from within the HoloLens 2 as the user is trying to grab a pickaxe; (c) view from the perspective of a third person who does not see the virtual display (photos by Connie Kwong, Lending Services and Learning Environments, Hong Kong University Libraries).

may be materially underrepresented or had more intangible heritage. Bruno and colleagues (2019) even experimented with applying AR to underwater sites in order to enhance the divingtourist's experience. Liestøl and colleagues (2018) used tablets to allow users to see how the sea level along the coast of Norway had changed over time while those users were standing in the actual landscape. Their app also linked to an online database providing multimodal information about archaeological sites of the Neolithic period. Dragoni and colleagues (2018) experimented with tablet-based AR technologies to determine performance parameters for overlaying real-scale Roman architecture on the in situ remains. Many other researchers have also experimented with using AR to guide tourists through archaeological sites and present locationally aware information superimposed on sites or objects in a landscape or museum (e.g., Morandi and Tremari 2017; Pierdicca et al. 2016).

Experiments have also begun with public engagement using MR, even though it may not yet be comfortable for visitors to wear an HMD such as the HoloLens for extended periods of time. Bekele's (2019) "walkable MxR Map" provided a room-sized map that was projected on the floor and viewed through the HoloLens. Users could be guided through a museum or heritage site to interact with cultural content using HoloLens methods such as gesture, gaze, and voice activation. Hammady and colleagues (2020) also deployed the HoloLens to increase the immersive experience of visitors to the famous Egyptian Museum in Cairo, enabling interaction with virtual guides at display cases where users could also manipulate virtual objects. This is only a small sampling of the examples of using $A R$ and MR in public engagement - the most developed subtopic of $A R$ and MR in archaeology - which has a long history of scholarly inquiry (Papagiannakis et al. 2005; Vlahakis et al. 2001).

Studies of other applications for AR and MR, however, hold out the much wider potential of our deployment of large 3D datasets for archaeology_including for data management and research applications. Dilena and Soressi (2020) demonstrated the potential and current limitations of large datasets of precisely positioned excavated artifacts. Although there are challenges due to memory and sensor constraints, they proposed using phone-based AR to place artifacts in the correct position at the real site, hovering above the ground where they were originally excavated-which 


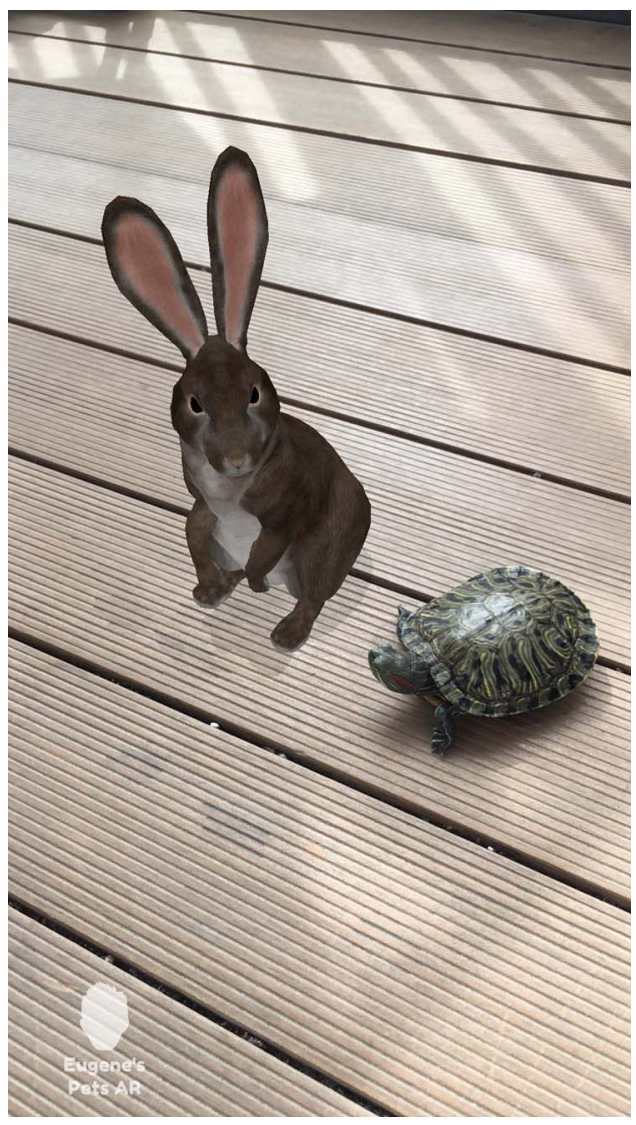

FIGURE 3. This AR phone app places a virtual 3D rabbit on a real surface next to a real turtle using the phone's camera (Eugene's Pets AR app).

we agree is one of the most powerful potential uses of $A R$ and, eventually, full immersive MR. Barbier and colleagues (2017) developed an annotation system to allow archaeologists to examine megalithic cave artwork remotely from the office or classroom. This project deployed the Microsoft HoloLens 1 to enable interaction with the stone surfaces, including the ability to write notes attached to specific locations on those surfaces. Given that the system works with the artifacts outside the original context and only engages with individual artworks, however, a VR setup would have been sufficient for this project because MR-specific functionality is not really engaged. Although visual interaction with sites is well developed for visitors, some researchers are turning their attention to using AR with other senses. Sikora and colleagues (2018) used headphones and a smartphone to give visitors a sense of what a medieval site would have sounded like. Eve (2017) enabled multisensory interaction with archaeological landscapes by adding sound and smell to the visual AR experience.

Brondi and colleagues (2016) attempted to use the HoloLens's gesture capabilities to enhance hands-on training in cultural heritage, particularly intangible culture. When using the device, a user follows the prerecorded hand movements of printmakers creating stamps or of weavers at a loom. The user's hands could be superimposed on the prerecorded hands to enhance the training by replicating each precise movement. This technique might also have

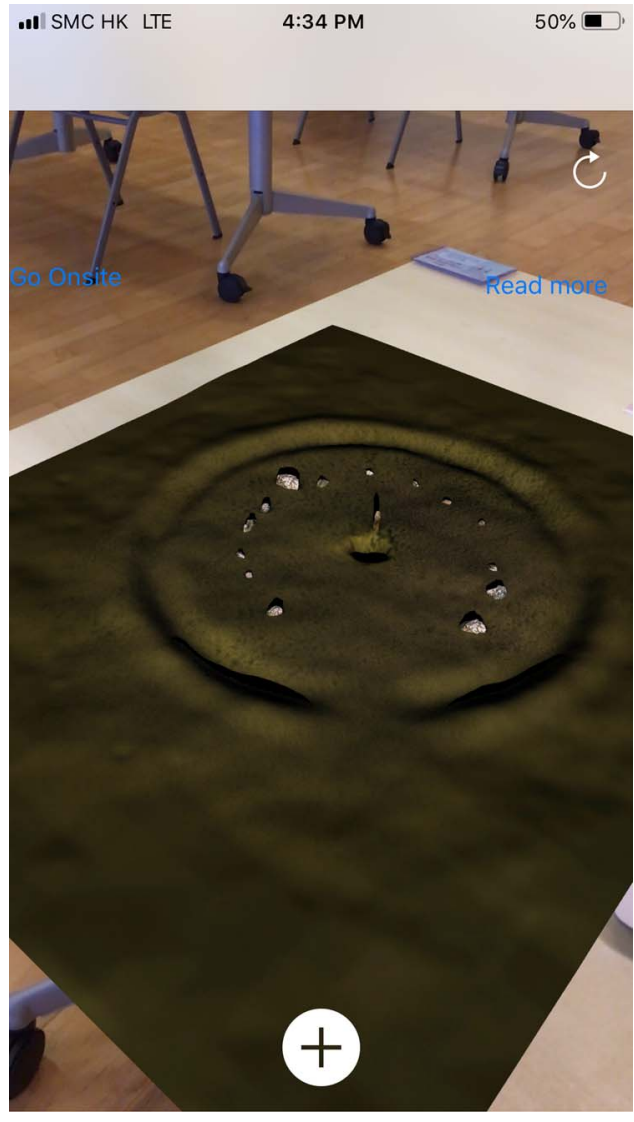

FIGURE 4. This AR phone app has placed a model of an ancient stone circle and henge virtually on a classroom desktop in Hong Kong. This is the Bryn Celli Ddu henge, a fourth to second millennium BC prehistoric site in Wales (Bryn Celli Ddu AR app).

application potential in training archaeological excavation methods or conservation treatments. An extremely promising example of the deployment of MR comes from Gaugne and colleagues (2019). The authors propose the novel application of using MR to guide a micro-excavation by allowing a user to "see inside" the excavation target-in this case, funerary urns. They used CT scan data to produce 3D visualizations of the solid objects buried within the dirt of an urn. With an MR projection of these 3D models, it would appear to the user that the objects are floating inside. Consequently, while excavating the actual urn, the user would see the precise location, size, and orientation of any object that was captured by the CT scan within the urn. This could greatly help to guide excavators' decisions as well as prepare them for when they begin to uncover each object. The authors note that training with MR could usefully reduce potential excavation damage, such as in situations where objects overlap or are in a very complex position. It would also allow for working time estimation.

\section{SOME CHALLENGES OF 3D DATA}

The recent proliferation of 3D datasets has encouraged new discussions on the ethical deployment of these models. One well- 


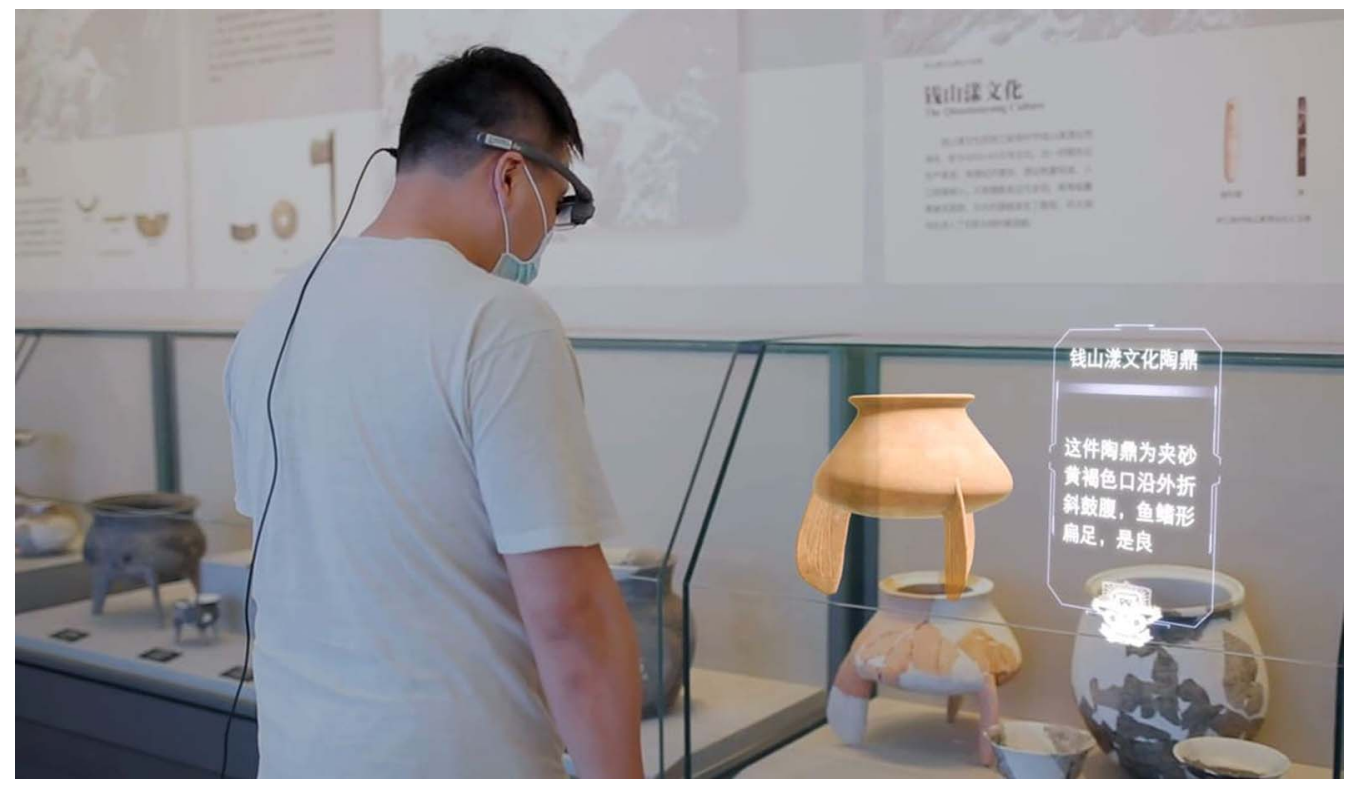

FIGURE 5. A museum visitor is looking at a ceramic vessel (ding) through an AR HMD at the Liangzhu Museum and Archaeological Site. The pop-up screen displaying the information about this pottery is in the user's view (image courtesy of Rokid; Exhibition Solutions 2021).

known case involved the Roman period triumphal arch in Palmyra, Syria, where digital methods were both celebrated for their preservation potential (Denker 2017) and critiqued for their tendency toward cultural appropriation (Kamash 2017). Recently, the Koç University Maritime Archaeology Research Center (KUDAR) and the American Research Institute in Turkey (ARIT) held an online discussion entitled "National Jurisdiction in the Digital Realm" (ARIT 2021). This conversation examined the dissemination of 3D digital models of cultural heritage that often represent national identities. The presenters considered the roles and relationships between nation states and individuals who can now build highfidelity 3D models, and they explored questions surrounding the control and ownership of those models. In addition, individual users can modify digital representations by adding, changing, and deleting 3D components of digital heritage based on personal preferences-how would this impact the dissemination of information about original cultural heritage?

Another consideration is who has access to the expensive technologies used to create accurate digital models, and who has the training to deploy these methods successfully (Kansa and Kansa 2021; Roosevelt et al. 2015:341). Because these technologies are new, specialists have only just begun to share information on how best to deploy them on archaeological projects. For example, Rahaman and colleagues (2019) and Douglass and colleagues (2019) offer comprehensive proposals for workflows to create 3D models from 2D imagery specifically for the purpose of cultural heritage deployment in MR. Close collaborations between archaeologists and digital specialists can also support our digital practice (Cobb et al. 2019).

Although 3D models can help to preserve information about the past and objects from the past, the creation of these large 3D datasets also often leads to the question of how to preserve the digital data themselves over the long term. We create digital heritage by conducting careful, time-consuming measurements to capture the highly accurate 3D data we need for research. Because 3D data hold similar importance to other types of digital or physical data, they should be preserved and made accessible (Kansa 2012). Nowadays, cloud storage systems simplify preservation by abstracting the physical storage mechanism and by enabling easy data replication, often geographically distributed (Mering 2015). Several international online archaeological repositories plan to store large datasets for an extended period of time (Galeazzi et al. 2016; McManamon 2017).

\section{LOOKING FORWARD}

Recent world events have highlighted the potential benefits that $\mathrm{XR}$ technologies can have when opening up remote interaction with archaeological sites and objects, especially for education and training. The global XR market is estimated to grow $18 \%$ each year until 2028 (Nigam 2021), and virtual museums (Romano 2020) and virtual site tours (Dziuba 2021) have quickly developed worldwide. Conferences (including those of the Society for American Archaeology) and other meetings have experimented with virtuality, and schools and universities are now experienced with providing both face-to-face and virtual courses. The increasing application of machine learning in archaeology should also help enable us to better use and interact with our large and complex 3D datasets (Bickler 2021). Given their ability to combine the real world of our present archaeological evidence with the virtual worlds of our interpretations of the past, AR and MR technologies are particularly well positioned to make contributions to our archaeological practice and research. Improved hardware will make the MR and AR experiences easier to use, more realistic, and more comfortable. And then, perhaps one day, archaeologists will 
naturally record new evidence and interact with previously removed evidence while using MR in situ.

\section{Acknowledgments}

I would like to thank Mr. Wong Chi-him Leo of the Lending Services and Learning Environment division of the University of Hong Kong Libraries, who kindly set up the HoloLens 2 for student experimentation and photography.

\section{REFERENCES CITED}

Amakawa, Jonathan, and Jonathan Westin

2018 New Philadelphia: Using Augmented Reality to Interpret Slavery and Reconstruction Era Historical Sites. International Journal of Heritage Studies 24:315-331.

American Research Institute in Turkey (ARIT)

2021 National Jurisdiction in the Digital Realm. American Research Institute in Turkey. Panel discussion. Moderator: Matthew Harpster (KUDAR and Koç University). YouTube video. Length 2:14:37. April 27, 2021. https://www. youtube. $\mathrm{com} /$ watch? $\mathrm{v}=\mathrm{AQvWRScH} 2 \mathrm{OM}$.

Aniwaa Pte. Ltd.

2021 The 9 Best Mixed Reality Headsets of 2021. Electronic document, https:// www.aniwaa.com/buyers-guide/vr-ar/best-mixed-reality-headsets/, accessed May 20, 2021

Azuma, Ronald T.

1997 A Survey of Augmented Reality. Presence: Teleoperators and Virtual Environments 6(4):355-385

Barbier, Johanna, Patricia Kenny, Jordan Young, Jean-Marie Normand, Mark T. Keane, Muiris O'Sullivan, and Anthony Ventresque

2017 MAAP Annotate: When Archaeology Meets Augmented Reality for Annotation of Megalithic Art. In 2017 23rd International Conference on Virtual System \& Multimedia (VSMM), edited by Lizbeth Goodman and Alonzo Addison, pp. 283-291. Institute of Electrical and Electronics Engineers, New York

Bekele, Mafkereseb Kassahun

2019 Walkable Mixed Reality Map as Interaction Interface for Virtual Heritage. Digital Applications in Archaeology and Cultural Heritage 15. DOI:10.1016/ j.daach.2019.e00127.

Bekele, Mafkereseb Kassahun, Roberto Pierdicca, Emanuele Frontoni, Eva Savina Malinverni, and James Gain

2018 A Survey of Augmented, Virtual, and Mixed Reality for Cultural Heritage. Journal on Computing and Cultural Heritage 11(2):1-36.

Bickler, Simon $\mathrm{H}$.

2021 Machine Learning Arrives in Archaeology. Advances in Archaeological Practice 9:186-191. DOI:10.1017/aap.2021.6.

Brondi, Raffaello, Marcello Carrozzino, Cristian Lorenzini, and Franco Tecchia 2016 Using Mixed Reality and Natural Interaction in Cultural Heritage Applications. Informatica 40(3):P.311.

Bruno, Fabio, Loris Barbieri, Marino Mangeruga, Marco Cozza, Antonio Lagudi Jan Cejka, Fotis Liarokapis, and Dimitrios Skarlatos

2019 Underwater Augmented Reality for Improving the Diving Experience in Submerged Archaeological Sites. Ocean Engineering 190:106487. DOI:10. 1016/j.oceaneng.2019.106487

Burdea, Grigore C., and Philippe Coiffet

2003 Virtual Reality Technology. John Wiley \& Sons, Hoboken, New Jersey.

Cobb, Peter J., John H. Sigmier, Petra M. Creamer, and Emily R. French

2019 Collaborative Approaches to Archaeology Programming and the Increase of Digital Literacy among Archaeology Students. Open Archaeology 5:137-154.

Denker, Ahmet

2017 Rebuilding Palmyra Virtually: Recreation of Its Former Glory in Digital Space. Virtual Archaeology Review 8(17):20-30.

Dilena, Miguel Angel, and Marie Soressi

2020 Reconstructive Archaeology: In Situ Visualisation of Previously Excavated
Finds and Features through an Ongoing Mixed Reality Process. Applied Sciences 10(21). DOI:10.3390/app10217803.

Douglass, Matthew J., Zachary R. Day, Jeremy C. Brunette, Peter Bleed, and Douglas Scott

2019 Virtual Reconstruction as Archaeological Observation: Embracing New Ways of Treating Sites, Places and Landscapes. Advances in Archaeological Practice 7:127-139.

Dragoni, Aldo F., Ramona Quattrini, Paolo Sernani, and Ludovico Ruggeri 2018 Real Scale Augmented Reality. A Novel Paradigm for Archaeological Heritage Fruition. In International and Interdisciplinary Conference on Digital Environments for Education, Arts and Heritage, edited by Alessandro Luigini, pp. 659-670. Springer, Cham, Switzerland.

Dziuba, Christine

2021 Educational \& Virtual Tours Resources List. Archaeological Institute of America. Electronic document, https://www.archaeological.org/virtualeducation-resources/, accessed May 3, 2021.

Ellenberger, Kate

2017 Virtual and Augmented Reality in Public Archaeology Teaching. Advances in Archaeological Practice 5:305-309.

Eve, Stuart

2017 The Embodied GIS: Using Mixed Reality to Explore Multi-Sensory Archaeological Landscapes. Internet Archaeology 44. DOI:10.11141/ia.44.3.

Exhibition Solutions

2021 Rokid. Electronic document, https://www.rokid.com/en/solution/ar/ exhibition/, accessed May 5th, 2021.

Fathi, Sami

2021 Kuo: Apple Still on Track to Release Mixed Reality Headset Next Year MacRumors. Electronic document, https://www.macrumors.com/2021/04/ 23/kuo-headset-on-track-for-next-year/, accessed April 23, 2021

Galeazzi Fabrizio, Marco Callieri, Matteo Dellepiane, Michael Charno, Julian Daryl Richards, and Roberto Scopigno

2016 Web-Based Visualization for 3D Data in Archaeology: The ADS 3D Viewer. Journal of Archaeological Science: Reports 9:1-11.

Gaugne, Ronan, Quentin Petit, Mai Otsuki, Valérie Gouranton, and Théophane Nicolas

2019 Evaluation of a Mixed Reality Based Method for Archaeological Excavation Support. In ICAT-EGVE 2019 International Conference on Artificial Reality and Telexistence and Eurographics Symposium on Virtual Environments, edited by Yasuaki Kakehi and Atsushi Hiyama, pp. 81-88. Eurographics Association, Tokyo.

Hammady, Ramy, Minhua Ma, Carl Strathern, and Mostafa Mohamad 2020 Design and Development of a Spatial Mixed Reality Touring Guide to the Egyptian Museum. Multimed Tools Applications 79:3465-3494. DOI:10.1007/s11042-019-08026-w.

Jayawardena, Amarananda Somasiri, and Indika Perera

2016 A Framework for Mixed Reality Application Development: A Case Study on Yapahuwa Archaeological Site. In 16th International Conference on Advances in ICT for Emerging Regions (ICTer) 2016, pp. 186-192. Institute of Electrical and Electronics Engineers, New York.

Kamash, Zena

2017 Postcard to Palmyra: Bringing the Public into Debates over Post-Conflict Reconstruction in the Middle East. World Archaeology 49:608-622.

Kansa, Eric

2012 Openness and Archaeology's Information Ecosystem. World Archaeology 44:498-520.

Kansa, Eric, and Sarah Whitcher Kansa

2021 Digital Data and Data Literacy in Archaeology Now and in the New Decade. Advances in Archaeological Practice 9:81-85. DOI:10.1017/aap. 2020.55.

Keil, Jens, Laia Pujol, Maria Roussou, Timo Engelke, Michael Schmitt, Ulrich Bockholt, and Stamatia Eleftheratou

2013 A Digital Look at Physical Museum Exhibits: Designing Personalized Stories with Handheld Augmented Reality in Museums. In 2013 Digital Heritage International Congress (DigitalHeritage), Vol. 2, edited by Alonzo C. Addison, Livio De Luca, Gabriele Guidi, and Sofia Pescarin, pp. 685-688. Institute of Electrical and Electronics Engineers, New York.

Liestøl, Gunnar, Birgitte Bjørkli, Sarunas Ledas, Tomas Stenarson, and Espen Uleberg 
2018 Archaeology and Augmented Reality. Visualizing Stone Age Sea Level on Location. In Proceedings of the 44th Conference on Computer Applications and Quantitative Methods in Archaeology, edited by Mieko Matsumoto and Espen Uleberg, pp. 367-377. Archaeopress, Oxford.

McManamon, Francis P., Keith W. Kintigh, Leigh Anne Ellison, and Adam Brin 2017 TDAR: A Cultural Heritage Archive for Twenty-First-Century Public Outreach, Research, and Resource Management. Advances in Archaeological Practice 5:238-249. DOI:10.1017/aap.2017.18.

Mering, Margaret

2015 Preserving Electronic Scholarship for the Future: An Overview of LOCKSS, CLOCKSS, Portico, CHORUS, and the Keepers Registry. Serials Review 41(4):260-265. DOI:10.1080/00987913.2015.1099397.

Milgram, Paul, Haruo Takemura, Akira Utsumi, and Fumio Kishino 1995 Augmented Reality: A Class of Displays on the Reality-Virtuality Continuum. In Telemanipulator and Telepresence Technologies, Vol. 2351, edited by Hari Das, pp. 282-292. International Society for Optics and Photonics, Bellingham, Washington

Morandi, Simona, and Marco Tremari

2017 Interactive Past: From 3D Reconstruction to Augmented and Virtual Reality Applied to Archaeological Heritage: The Medieval Site of Bastia St. Michele (Cavaion Veronese, Verona, Italy). In 2017 23rd International Conference on Virtual System and Multimedia (VSMM), edited by Lizbeth Goodman and Alonzo Addison, pp. 247-255. Institute of Electrical and Electronics Engineers, New York.

Nigam, Sameer

2021 Mixed Reality Is Setting the Stage for E-Learning \& Training in a Post-COVID-19 World. Entrepreneur, April 9. Electronic document, https:// www.entrepreneur.com/article/369019, accessed April 19, 2021.

Papagiannakis, George, Sebastien Schertenleib, Brian O'Kennedy, Marlene Arevalo-Poizat, Nadia Magnenat-Thalmann, Andrew Stoddart, and Daniel Thalmann

2005 Mixing Virtual and Real Scenes in the Site of Ancient Pompeii. Computer Animation and Virtual Worlds 16(1):11-24. http://dl.acm.org/citation.cfm? id $=1071146$

Pierdicca, Roberto, Emanuele Frontoni, Primo Zingaretti, Eva Savina Malinverni, Andrea Galli, Ernesto Marcheggiani, and Carlos Smaniotto Costa

2016 Cyberarchaeology: Improved Way Findings for Archaeological Parks through Mobile Augmented Reality. In International Conference on
Augmented Reality, Virtual Reality and Computer Graphics, edited by Lucio Tommaso De Paolis and Antonio Mongelli, pp. 172-185. Springer, Cham, Switzerland.

Rahaman, Hafizur, Erik Champion, and Mafkereseb Bekele

2019 From Photo to 3D to Mixed Reality: A Complete Workflow for Cultural Heritage Visualisation and Experience. Digital Applications in Archaeology and Cultural Heritage 13. DOI:10.1016/j.daach.2019.e00102.

Romano, Andrea

2020 Stuck at Home? These 12 Famous Museums Offer Virtual Tours You Can Take on Your Couch (Video). Travel + Leisure, March 12. https://www. travelandleisure.com/attractions/museums-galleries/museums-with-virtualtours, accessed May 3, 2021.

Roosevelt, Christopher H., Peter Cobb, Emanuel Moss, Brandon R. Olson, and Sinan Ünlüsoy

2015 Excavation Is Destruction Digitization: Advances in Archaeological Practice. Journal of Field Archaeology 40:325-346

Sikora, Marjan, Mladen Russo, Jurica Đerek, and Ante Jurčević

2018 Soundscape of an Archaeological Site Recreated with Audio Augmented Reality. ACM Transactions on Multimedia Computing, Communications, and Applications 14(3):1-22.

Speicher, Maximilian, Brian Hall, and Michael Nebeling

2019 What Is Mixed Reality? In Proceedings of the 2019 CHI Conference on Human Factors in Computing Systems, pp. 1-15. Association for Computing Machinery, New York.

Vlahakis, Vassilios, John Karigiannis, Manolis Tsotros, Michael Gounaris, Luis Almeida, Didier Stricker, Tim Gleue, loannis T. Christou, Renzo Carlucci, and Nikos loannidis

2001 Archeoguide: First Results of an Augmented Reality, Mobile Computing System in Cultural Heritage Sites. In Proceedings of the 2001 Conference on Virtual Reality, Archeology, and Cultural Heritage, pp. 131-140. Association for Computing Machinery, New York.

\section{AUTHOR INFORMATION}

Jiafang Liang $\square$ Faculty of Education, Room 402, 4/F, Meng Wah Complex, University of Hong Kong, Pokfulam Road, Hong Kong (liangjfj@connect.hku.hk) 